\title{
El legado de la oligarquía y la herencia de las dictaduras
}

\section{Claudia González Castro}

Universidad San Sebastián, Valdivia, Chile.

Email: claudia.gonzalez@uss.cl

Resumen: Reflexionando acerca de lo propiamente latinoamericano, advertimos en el continente condiciones históricas similares que habrían favorecido los regímenes autoritarios que la literatura acusa como pulsión libertaria, aflorando en las narrativas como pretexto para repensarlas una y otra vez, hasta fundirse ficción y realidad con la identidad, conformando parte determinante de aquello que se considera propiamente latinoamericano.

Palabras clave: Latinoamericanismo, literatura latinoamericana, identidad latinoamericana, dictaduras latinoamericanas, historia latinoamericana.

\section{The legacy of oligarquy and the heritage of dictatorships}

\begin{abstract}
On thinking about what is strictly Latin-American, we can see in the continent the presence of similar historical conditions which would have favored authoritarian regimes; those that literature accuse as having libertarian drives, emerging thus in the narratives as a pretext to rethink them over and over, until merging fiction and reality with identity, shaping a large part of what is considered to be proper to Latin-American.
\end{abstract}

Keywords: Latin-Americanism, latin-american literature, latin-american identity, latin-american dictatorships, latin-american history.

\section{O legado da oligarquia e a herença das ditaduras}

Resumo: Refletindo sobre o propriamente Latino-americano, advertimos nocontinente condições históricas semelhantes que teriam favorecido os regimes autoritários que a literatura acusa como impulso libertário, surgindo nas narrativas como um pretexto para repensa-las uma e outra vez, até que elas misturem a ficção e a realidade com a identidad, conformando parte determinante daquilo que é considerado próprio da América Latina.

Palavras-chave: Latino-americanismo, literatura latino-americana, identidade latino-americana, ditaduras latino-americanas, história latino-americana.

Nuestra historia, entendida como una mirada retrospectiva comunitaria a través del tiempo, está construida sobre la memoria y el olvido colectivo. Mientras la memoria, cohesiona y le da linealidad, el olvido escinde, divide y establece rupturas. Augé (1998), reconoce tres formas de olvido, que se expresan en las figuras del retorno, el suspenso y el comienzo. Retor- 
nar -la primera de las formas de olvido- se define en este contexto, como la recuperación del pasado más antiguo y el olvido del presente. Suspender la segunda forma- se desplaza a través del olvido hacia el futuro, aislando memorias, confinando recuerdos, para transitar por sobre ellos en el tiempo. Por último, el comienzo, olvida el pasado, fundando un futuro cimentado sobre el presente. Desde la figura del suspenso, el ejercicio del olvido ha sido ejercido en Chile, acallando un pasado que emerge en el recuerdo y como un trauma social, se manifiesta arraigado en los sentidos colectivos, lo identitario y lo propiamente latinoamericano. Episodios traumáticos, efecto de gobiernos autoritarios, surgen en el recuerdo iterativamente, hasta convertirse en un leitmotiv, del arte, la literatura y el espacio comunicacional, integrándose a nuestro imaginario social como un componente fundamental de nuestro latinoamericanismo.

Ningún continente parece estar tan cohesionado históricamente como el nuestro, en el que cada periodo histórico, es la réplica o el anticipo del país vecino. Las dictaduras militares, herederas del sistema oligárquico, agregan una particularidad difícil de explicar en la historia americana, pero que a todos nos resulta altamente significativo y que permite entenderlas como consecuencia de un derrotero común, o una determinada forma de habitar el continente. A pesar de ser factible identificar ciertos periodos cronológicos de convergencia histórica, no es la intención de este ensayo examinar un periodo decenal determinado, sino exponer ciertos fenómenos comunes de la región, efecto de una determinada forma que adquiere el ejercicio gubernamental en este espacio. Para ello es apropiado pensar un criterio de temporalización indiferente a la cronología, considerando que cada época tiene acontecimientos que le son propios, que son los que guían esta reflexión, y que le dan coherencia, más allá de los auxiliares cronológicos de clasificación (Kosellec, 1998). El propósito de este ensayo es reconocer algunas características que son propias de la oligarquía y las dictaduras latinoamericanas para explicar la unicidad del fenómeno histórico y posteriormente identificar su emergencia como expresión del trauma social, en la forma de un leitmotiv del arte y otras manifestaciones culturales, pero que para efectos de este trabajo, remitiremos a la literatura americana. Hablaremos de “oligarquías” y “dictaduras militares” unificadas en una sola descripción que se adapta a todas las prácticas del continente, que más allá de una experiencia política, son también económica, ideológica y social, conformando una sensibilidad común a toda América Latina, cuyo análisis nos entrega un recurso más para la comprensión de nuestra identidad.

\section{De la oligarquía a la Dictadura}

Un determinante de los regímenes militares es la idea de jerarquía social, herencia ideológica y económica de la clase social oligárquica. En los primeros pasos de los estados independientes de América latina, se establece un nuevo grupo de dominio entre los emergentes comerciantes, mineros, hacendados y cafetaleros, con sus respectivas consecuencias. La Oligarquía tuvo un extenso periodo de desarrollo y predominio en el que 
primeramente capturaron el poder económico con la explotación de recursos y la consiguiente acumulación de capital entre familias, para posteriormente conquistar el poder del estado. De esta manera, la capacidad de decisión se concentraba en un grupo social reducido, vinculado familiarmente. En los relatos historiográficos del periodo de modernización figuran dinastías como la de Melendez-Quiñones, cafetaleros de El Salvador; los Cousiño, carboníferos en Chile; los Gildemaister, salitreros en Perú; los Santamarina, terratenientes en Argentina, y otras familias enriquecidas efecto de la activación del comercio exterior con la sociedad europea de la era industrial, que junto al protagonismo económico erigen un poder simbólico detentado a través de una determinada forma de vida, basada en el lujo y la arrogancia, que los caracterizó como referentes sociales.

Los Ventura tuvieron muchos mayordomos, todos idénticos: nadie recordaba ni sus nombres ni sus características personales porque sus deberes estaban tan reglamentados que automáticamente se era un Mayordomo perfecto dado cierto número de años de servicio. Lo que nadie olvidaba, sin embargo lo que no abandonaba sus pesadillas de niños ni sus obsesiones de grandes, era la célebre librea del Mayordomo (...) Esta librea era tan enorme que lo que en verdad resultaba difícil era encontrar un candidato de talla suficiente para que no quedara suelta. Una vez cumplidos este requisito y el entrenamiento debido, se podía contar con que todos los Mayordomos fueran igualmente sin iniciativas que pretendieran innovar los rituales, y que no aspiraran a otro emolumento que el honor de ser lo que eran, y a la casita que en la capital, como premio, los Ventura les obsequiaban en un barrio semejante al barrio donde vivían los señores, pero plebeyo, con fachadas ordinarias que remedaban las fachadas nobles alineadas en las grandes avenidas de palmeras que habitaba la gente como los Ventura (Donoso, 1978/1998:45)

La oligarquía, no fue una clase social propiamente tal, sino más bien, una categoría política, que cohesionados por sus intereses económicos ejercieron opresión y dominio. Organizaron la sociedad a partir del concepto de hacienda como cónclave de la institución familiar. Establecieron además una particular forma de relación entre empleador-empleado (inquilinaje en sectores rurales) con fuerte dependencia económica y un naturalizado ejercicio de la coerción física.

El poder económico de la oligarquía prontamente trascendió a lo político, ya que la apropiación y control de la masa trabajadora le permitió utilizarla como estrategia en las contiendas electorales haciendo uso del voto de sus obreros (Cavarozzi, 1978). Sin duda, este modelo de relación laboral ha dejado marcas indelebles en el inconsciente colectivo latinoamericano, que emerge como recuerdo traumático en la literatura, en textos como Casa de Campo (Donoso, 1978), La Casa de Los Espíritus (Allende, 1982), que narran el inquilinaje campesino y sus relaciones de opresión y sumisión. Por otra parte, Baltazar Castro y Baldomero Lillo, escriben sobre 
la traumática experiencia de los trabajadores mineros en Sewel (1953) y SubTerra (1904). Junto al trauma del martirio y explotación del trabajador, América Latina conserva una singular manera paternalista de relacionarse con las clases privilegiadas y sus valores asociados, como el dinero y el poder.

En el transcurso de los diez años siguientes, Esteban Trueba se convirtió en el patrón más respetado de la región, construyó casas de ladrillo para sus trabajadores, consiguió un maestro para la escuela y subió el nivel de vida de todo el mundo en sus tierras. (...) El mal carácter de Trueba se convirtió en una leyenda y se acentuó hasta llegar a incomodarlo a él mismo. No aceptaba que nadie le replicara y no toleraba ninguna contradicción, consideraba que el menor desacuerdo era una provocación. También se acrecentó su concupiscencia. No pasaba ninguna muchacha de la pubertad a la edad adulta sin que la hiciera probar el bosque, la orilla del río, o la cama de fierro forjado (...) Los campesinos escondían a las muchachas y apretaban los puños inútilmente, pues no podían hacerle frente. Esteban Trueba era más fuerte y tenía impunidad. Trueba siguió labrando su prestigio de rajadiablos, sembrando la región de bastardos, cosechando el odio y almacenando culpas que no le hacían mella, porque se le había curtido el alma y acallado la conciencia con el pretexto del progreso (Allende, 1982/2007: 88)

La explotación de los estratos sociales bajos, a través del inquilinato (agrícola) o el esclavismo (cafetalero) contribuyeron a la construcción de una idea de poder político-económico hegemónico, centralizado y paternalista, alrededor del cual se ampara la población, en una relación de supervivencia, que comprendía además, fidelidad y sumisión, trascendiendo de lo material, hacia lo ideológico. Es importante mencionar que las oligarquías desarrollaron exclusivamente el modelo monoproductor. La aguda dependencia de la exportación de monocultivos como el café y el azúcar en Centro América, y la explotación del salitre y el estaño en América del Sur, generó la gran crisis económica durante la primera guerra mundial, cuando Europa redujo considerablemente el nivel de importaciones, arrastrando consigo el derrumbe del modelo, el empobrecimiento de los países del continente americano y su consiguiente retraso tecnológico respecto a Europa. La idea de modernización neoliberal y capitalista será la apuesta fundamental de las dictaduras militares en Latinoamérica.

Durante el predominio de la clase oligárquica, los Estados debieron enfrentar una serie de conflictos de clase (la amplia brecha social abre paso a la lucha social); conflictos étnicos (el despojo de tierras indígenas y su consiguiente descontento) y territoriales (como la Guerra del Pacífico del cono sur por el dominio de las salitreras) que generaron la necesidad de una fuerza que apoyara y resguardara sus intereses políticos y económicos. Para ello, la oligarquía invirtió en la formación e instrucción de un ejército que hasta entonces no existía. La prosperidad del momento facilitó una inversión cuantiosa en la profesionalización militar en la línea germánicoprusiana, reorientando la formación militar que existía hasta el momento, 
conformando un cuerpo militar al servicio de los intereses e ideología de la clase oligárquica. En lo económico, resguardó sus intereses de clase; en lo racial se hace parte del menosprecio y el despojo del indígena; en lo social, es un agente represivo de la contienda social y en lo político, aprueba el autoritarismo y el empleo legítimo de la violencia (Quiroga, 2002).

La prusianización del ejército erigió la imagen del militar-autoridad, con participación política y legítimo poder represivo, que se adosará al imaginario Latino Americano en su desarrollo histórico y potenciará las dictaduras. El pacto colaborativo entre clase dominante y milicia permitieron un acuerdo apropiado para excluir a los sectores rurales y a las clases trabajadoras urbanas del empoderamiento político y la repartición de privilegios sociales, logrando un control extremo de la economía y las decisiones gubernamentales. Algunas regiones dividieron las tareas de gobierno: militares ejercían el poder político y comerciantes exportadores, junto a sectores de clase media urbana, controlaban la economía, respetándose y colaborándose entre ellos (Bradford, 1985). Las agudas diferencias sociales y la pauperización del trabajador decantaron en la cuestión social. La llegada de ideas marxistas significó posteriormente la lucha armada (revolución cubana, movimientos guerrilleros en Perú, Bolivia y Venezuela), con un trabajador convertido en proletario, contra una oligarquía convertida en Burguesía. Sin haber vivido un proceso de revolución industrial, América Latina se comprendió a sí misma desde la lucha de clases, con dramáticos enfrentamientos que la literatura se encarga de rememorar.

José Arcadio Segundo estaba entre la muchedumbre que se concentró en la estación desde la mañana del viernes. Había participado en una reunión de los dirigentes sindicales y había sido comisionado junto con el coronel Gavilán para confundirse con la multitud y orientarla según las circunstancias. No se sentía bien, y amasaba una pasta salitrosa en el paladar, desde que advirtió que el ejército había emplazado nidos de ametralladoras alrededor de la plazoleta, y que la ciudad alambrada de la compañía bananera estaba protegida con piezas de artillería. Hacia las doce, esperando un tren que no llegaba, más de tres mil personas, entre trabajadores, mujeres y niños, habían desbordado el espacio descubierto frente a la estación y se apretujaban en las calles adyacentes que el ejército cerró con filas de ametralladoras (...) Cuando José Arcadio Segundo despertó estaba bocarriba en las tinieblas. Se dio cuenta de que iba en un tren interminable y silencioso, y de que tenía el cabello apelmazado por la sangre seca y le dolían todos los huesos. Sintió un sueño insoportable. Dispuesto a dormir muchas horas, a salvo del terror y el horror, se acomodó del lado que menos le dolía, y solo entonces descubrió que estaba acostado sobre los muertos (García Márquez, 1967/2008: 365-366)

La llegada del pensamiento socialista a Latinoamérica, trae consigo demandas armadas, manifestaciones masivas y la aparición del populismo, encarnado en figuras como la de Odría en Perú y Perón en Argentina. 
Aquellos países que no articularon conflictos armados, desarrollaron una "lucha preventiva" contra las guerrillas revolucionarias. Combatir la expansión de las izquierdas fue uno de los principales móviles militares. Los sectores conservadores asignaron a las Fuerzas Armadas la represión de los movimientos insurgentes aprobando con unanimidad el uso de la violencia sin medida. Había nacido en América Latina, el principal enemigo de los dictadores: el marxismo. Con la izquierdización de la región, los países llegaron a polarizarse hasta el punto dividirse en, literalmente, dos bandos que mantenían un conflicto de carácter clasista, institucional y político, definiendo las contiendas de las próximas décadas (Cotler, 1977). Sin embargo el marxismo, en un territorio fuertemente marcado por el sincretismo, se funde con el catolicismo hasta convertirse en una extraña amalgama de religión y política, en la que el socialismo es el evangelio. Los marxistas latinoamericanos, más que un aporte a la teoría, entregan un tinte místico a la doctrina, que se traduce en una particular forma de ser apóstol-marxista en América. Mariategui (1972) contribuye a la visión religiosa de la izquierda desplazando el carácter científico atribuido por el marxismo ortodoxo hacia la fe y la pasión mística religiosa y espiritual. La unión entre izquierda y religión se consagra en la Teoría de la Liberación con representantes como Ernesto Cardenal (Nicaragua, 1925), Enrique Dussel (Argentina, 1934) y Fernando Lugo (Paraguay, 1951) quienes levantan un cuerpo teórico teológico comprometido socialmente.

Padre nuestro que estás en el exilio

casi nunca te acuerdas de los míos de todos modos dondequiera que estés

santificado sea tu nombre

no quienes santifican en tu nombre

cerrando un ojo para no ver las uñas

sucias de la miseria

(Benedetti, 1961/:57)

Las dictaduras emergen como una manera de enfrentar el desarrollo de los movimientos socialistas que irrumpen en los años 30, con el componente posterior de la guerra fría y la consolidación de Estados Unidos como potencia internacional tras la segunda guerra mundial. Efectivamente, el posicionamiento de EEUU en la jerarquía mundial, es determinante al examinar los golpes de estado militares avalados por Norte América. Lo habitual era que militares buscaran el consentimiento de la embajada norteamericana antes de dar el golpe de estado, de esta forma obtener una mayor legitimidad y reconocimiento internacional. Esto, sin contar con los quiebres del orden institucional que fueron directamente impulsados desde Washington. Estados Unidos reforzó la posición de los golpistas invirtiendo millones de dólares en los ejércitos latinoamericanos, especialmente con préstamos que permitieron renovar el vetusto armamento disponible. Una excepción a esta situación la protagoniza Perú y el levantamiento militar de 1968. Las determinaciones del Gobierno Revolucionario de las Fuerzas Armadas, lejos de contar con el apoyo norteamericano, significaron tensiones gubernamentales que fueron solucionadas posteriormente por la vía diplomática. 
Pero si las Dictaduras llegan a concretarse, no es tan solo por el apoyo norteamericano, es porque encontraron un espacio apropiado en la sociedad latinoamericana, heredera de las fuertes diferencias sociales de la etapa oligárquica. Una sociedad jerarquizada, que hereda el paternalismo benefactor de la clase gubernamental y el autoritarismo militar prusiano. Una sociedad que hereda también el desprecio hacia el indígena, que si bien se mantuvo siempre en lucha constante por el acceso a la tierra, fueron las dictaduras quienes reprimieron con mayor fuerza a las comunidades existentes. Todas ellas son huellas indelebles que se manifestarán en la búsqueda constante de la superación de las desigualdades, inequidades expresadas en la institucionalidad, hasta llegar a identificarse como una característica propia de los países denominados

\section{La Imagen del Dictador}

Aunque la presencia militar es constante en toda la historia de la América independiente, es en las décadas de los 60 y los 70 que los golpes militares se repitieron frecuentemente. Un general, o coronel, con apoyo de sus compañeros se lanzaba a la conquista del poder, o bien una corporación militar en pleno, intervenía en la vida política. Sin embargo, y a pesar de resaltar que las intervenciones han sido generalmente corporativas, en el imaginario Latinoamericano ha perdurado indeleble la figura del Dictador. No se puede dejar de reconocer la incidencia de las características personales del dictador en la percepción de los periodos autoritarios. El dictador asume el rol de líder de un grupo político asociado a la burguesía, al conservadurismo, o a la derecha. Personalidades obsesivas, egocéntricas, con componentes sicopáticos, de alto carisma y poder de convencimiento. Los dictadores encarnan la fantasía paternalista del protector-benefactor del pueblo, que en lógica de "El Príncipe” de Maquiavelo, se atribuyen atributos de sabiduría para guiar al resto de los ciudadanos. El poder se concentra en el dictador, aunque será común observar a otros representantes ejerciendo la dirección del país, manipulado por el verdadero cabecilla del gobierno. Esta modalidad de ejercer el poder desde un cargo paralelo a la presidencia se utilizó frecuentemente para "blanquear” las imágenes democráticas del país. Stroessner en Paraguay, Videla en Argentina, Pinochet en Chile, Trujillo en República Dominicana, proyectan una perturbadora imagen humana que ha sido objeto constante de la literatura, intentado aprehender las distorsionadas personalidades de dictadores.

No es que yo crea que el pueblo me erigió esta estatua porque yo sé mejor que vosotros que la ordené yo mismo.

Ni tampoco que pretenda pasar con ella a la posteridad porque yo sé que el pueblo la derribará un día.

Ni que haya querido erigirme a mí mismo en vida el monumento que muerto no me erigiréis vosotros: sino que erigí esta estatua porque sé que la odiáis.

(Cardenal, 1961/1972:45) 


\section{Represión y Derechos Humanos}

Las dictaduras militares, más allá del modelo económico y político impuesto y el considerable retraso artístico-cultural, el principal legado se refiere al trauma social de los derechos humanos que marca a América Latina, incorporando a la memoria colectiva el horror de la tortura. Todas las dictaduras latinoamericanas fueron sangrientas. En un proceder que acusa la formación alemana nazi que legitima la posibilidad de eliminar físicamente y por medios legales, al que se considere enemigo. El apoyo de la violencia fue utilizado en diferentes etapas del régimen y de diferentes maneras. En Argentina, Chile y Uruguay la represión comenzó junto con el derrocamiento de los gobiernos constitucionales y fue la principal herramienta utilizada para imponerse frente a una debilitada izquierda, efecto de las detenciones, ejecuciones focalizadas en líderes insurgentes. En Brasil, la represión se utilizó en las etapas finales para aplastar los focos guerrilleros levantados durante los cuatro años anteriores de dictadura, mientras que en Uruguay se vivió una represión dirigida al control de la sociedad civil, a través de la censura (Gutiérrez y Villegas, 1998). La metodología represiva eliminó toda posibilidad de disidencia política y se materializó a través de figuras ilegales como detenciones y secuestros, seguidos, en la mayoría de los casos de homicidios, desapariciones y tortura de las víctimas, generalmente pertenecientes a partidos comunistas, socialistas, e integrantes de focos guerrilleros. La represión militar se potenció a través de la articulación entre dictadores americanos, para establecer una organización represiva internacional (Operación Cóndor) que ejecutó un plan sistemático y minuciosamente organizado para lograr la vigilancia, detención y tortura de los opositores al régimen, más allá de las fronteras de cada país.

En El Nueve lo desnudaron y sentaron en la silla negruzca, en el centro de una habitación sin ventanas y apenas iluminada. El fuerte olor a excremento y a orines le dio náuseas. La silla era deforme y absurda, con sus añadidos. Estaba empotrada en el piso y tenía correajes y anillos para sujetar los tobillos, las muñecas, el pecho y la cabeza. Sus brazos estaban revestidos de placas de cobre para facilitar el paso de la corriente. Un manojo de cables salía del Trono hasta un escritorio o mostrador, donde se controlaba el voltaje (...) Entre sesión y sesión de silla eléctrica, lo arrastraban, desnudo, a un calabozo húmedo, donde baldazos de agua pestilente lo hacían reaccionar. Para impedirle dormir le sujetaron los párpados a las cejas con esparadrapo. Cuando, pese a tener los ojos abiertos, entraba en semiinconsciencia, lo despertaban golpeándolo con bates de béisbol. Varias veces le embutieron en la boca sustancias incomestibles; alguna vez detectó excremento y vomitó. Luego, en ese rápido descenso a la inhumanidad, pudo ya retener en el estómago lo que le daban (Vargas Llosa, /2000:463-465) 
El modelo monoproductor-exportador que explotó la etapa oligárquica, concluyó con el empobrecimiento y retraso de los países centro y sudamericanos, por lo que la carta de presentación de las dictaduras fue la modernización infraestructural, la apertura a los mercados internacionales y la inserción de la idea de progreso a cualquier precio. Esto último, es efectivamente literal al examinar las políticas de endeudamiento llevadas a cabo, que posteriormente azotaron al continente con la "deuda externa”. La ruta hacia el progreso, unido a la inyección de un componente ideológico "nacionalista” determinó también las largas décadas de dictaduras militares latinoamericanas. Curiosamente, la reformulación del aparato productivo, con los consecuentes cambios del modelo económico que instauraron las Dictaduras Militares, enterraron definitivamente a la clase oligárquica que fue, paradójicamente quien permitió el ingreso de las Dictaduras a América Latina.

\section{Conclusión}

Revisar la literatura latinoamericana y sus leitmotivs sociales nos hace pensar los episodios de autoritarismo y represión como parte de la identidad latinoamericana sublimada, o al menos como parte de un imaginario común sobre el cual construimos identidad y que cada cierto tiempo emerge como trauma. Freud (1905) desarrolló el concepto de Trauma Psíquico como explicación de los síntomas neuróticos, vivencias e impresiones no procesadas psíquicamente que dejan marcas, como restos no elaborados, en los estratos inconscientes más profundos del aparato psíquico. Experiencias que no pueden ser integradas, por tanto irrepresentables, cuyo síntoma característico es la re-experimentación del acontecimiento traumático a través de recuerdos dolorosos, invasivos y recurrente en sueños, que son narrados como relato metafórico del trauma. La literatura sobrepoblada de historicidad constituiría una forma de transitar experiencias entre el consciente y el inconsciente que en el repetitivo emerger nos sugiere su eterna latencia en nuestra conciencia.

La narración iterativa de los procesos autoritarios implica un espacio insuficientemente historizado, que acude a la ficción, para ejercitar el reconocimiento colectivo de la experiencia común del dolor. Cuando la historiografía falla, se fabulan historias para suplir sus deficiencias, en las cuales se puede leer la verdad escondida en las mentiras humanas (Vargas Llosa, 2002:14). Entonces el límite entre la verdad y la ficción se vuelve irrelevante pues la literatura no es más que la representación vicaria del acontecimiento que necesita ser visibilizado.

Distintos autores han interpelado la identidad de América Latina. Berrios (1988), lo hizo desde la especificidad de una percepción de la libertad que emergió como problema desde el primer movimiento revolucionario de la independencia americana. Tomando esta idea como referencia, podemos concluir que la esencia de un continente fuertemente 
embestido por eventos autoritarios, es la libertad, como problema, como objetivo, como trauma relegado al inconsciente. La historia común sobre el cual construimos nuestra identidad, ha nutrido pulsiones rebeldes, que cada cierto tiempo y en diferentes periodos históricos (conquista, dictaduras, lucha armada) se potencian, determinando la historia del continente y dejando una vez más la libertad al centro de la utopía. 


\section{Bibliografía}

Augé, M. (1998), Las Formas del Olvido, Ed. Gedisa, Barcelona

Allende, I. (2007), La casa de los espíritus, Sudamericana, Buenos Aires (1º ed. 1982).

Burns, B. (1985), La Modernización del Subdesarrollo: El Salvador, 18581931. Instituto de Estudios Contemporáneos, Santiago de Chile.

Benedetti, M. (2000), Poemas del hoyporhoy, Sudamericana, Buenos Aires ( $1^{\circ}$ ed. 1961$)$

Berrios, M. (1988), Identidad, origen, modelos: pensamiento latinoamericano, Instituto Profesional de Santiago, Santiago de Chile.

Cardenal, E. (1972), Epigramas, Ed. Carlos Lohlé, Buenos Aires (1º ed. 1961).

Cavarozzi, M. (1978), “El Orden Oligárquico en Chile”, 1880-1940, en Desarrollo Económico N ${ }^{\circ} 70$, FLACSO, Santiago de Chile.

Cotler, J. (1977), “Perú: Estado Oligárquico y Reformismo Militar”, en América Latina, Historia de Medio Siglo, Siglo XXI Editores, México.

Donoso, J. (1998), Casa de Campo, Alfaguara, Santiago de Chile, (1 ${ }^{\circ}$ ed 1978)

Freud (1992) Obras Completas, Vol 7, Amorroutu, Buenos Aires, (1 ${ }^{\circ}$ ed. 1905)

García Márquez, G. (2008), Cien años de soledad, Sudamericana, Bogotá, (1ºd. 1967).

Gutiérrez Contreras J. C. y Villegas Díaz, M. (1998), “Derechos humanos y desaparecidos en dictaduras militares”, en América Latina Hoy, vol 20, Universidad de Salamanca, España.

Koselleck, R. (1998), Futuro pasado. Para una semántica de los tiempos históricos, Paidos, Barcelona.

Quiroga, P. (2002), “El Predominio de las Oligarquías y la Prusianización de los Ejércitos de Chile y Bolivia (1880-1930)”, en Estudios Historiográficos, año $1, \mathrm{~N}^{\circ}$ 1, Universidad de Valparaíso, Valparaíso.

Vargas Llosa, M. (2000), La Fiesta del Chivo, Alfaguara, Santiago. 
Polis, Revista Latinoamericana, Volumen 14, No 41, 2015

Idem (2011), La verdad de las mentiras, Alfaguara, Madrid, (1ºd. 2002).

Recibido: 10.04.2013

Aceptado: 15.07.2014 